\title{
Aviones y drones: el elemento aéreo en Carl Schmitt
}

\author{
Planes and drones: the aerial element in Carl Schmitt
}

\author{
LAILA YOUSEF SANDOVAL*
}

Resumen: En la teoría internacional de Carl Schmitt la configuración política está condicionada por el espacio. Si bien el esquema de la Modernidad, articulado en torno a los diferentes tipos de guerra que surgían de la dicotomía tierra-mar, queda alterado con la incorporación de la aviación, será el uso de drones lo que pondrá en entredicho las nociones mismas de «campo de batalla», «soldado» o «enemigo». La realidad del dron desborda las coordenadas schmittianas, pero estas pueden servir como punto de partida para comprender cómo el espacio determina la guerra contemporánea.

Palabras clave: Carl Schmitt, Ius publicum europaeum, guerra terrestre, guerra marítima, guerra aérea, drones.

\begin{abstract}
In Carl Schmitt's international thought the political configuration is conditioned by space. Even though the blueprint of Modernity, articulated around the different politics that emerged from the land-sea dichotomy, rested altered with the incorporation of aviation, it will be the use of drones which will cast serious doubts on the notions of «battleground», «soldier» or «enemy». The reality of drones overflows the Schmittian coordinates, nevertheless they can be useful as starting point in order to understand how space determines contemporary war.
\end{abstract}

Keywords: Carl Schmitt, Ius publicum europaeum, land warfare, naval warfare, aerial warfare, drones.

\begin{abstract}
«En general, los talibanes veían los drones como una manera cobarde de luchar. Decían, ¿por qué los americanos no vienen a combatirnos sobre el terreno? [...] Entiendo cómo debe ser de frustrante para los soldados americanos. Aun así, los talibanes interpretaban el uso de drones como una manera de evitar la lucha cara a cara».
\end{abstract}

DAVID ROHDE ${ }^{1}$

Recibido: 10/05/2016. Aceptado: 13/10/2016.

* Laila Yousef Sandoval es doctora en Filosofía cum laude y con mención europea por la Universidad Complutense de Madrid. Actualmente es profesora de Ethics y Business Research and Analysis en la universidad americana CIS-Endicott en Madrid. Fue becaria predoctoral (FPU, Formación del Profesorado Universitario, Ministerio de Educación) de la Facultad de Filosofía de la Universidad Complutense de Madrid. Email: lailayousefsandoval@ gmail.com. Su investigación se centra en la evolución de los conceptos de las Relaciones Internacionales y en el pensamiento de Schmitt, Derrida y Kant, entre otros autores. Entre sus últimas publicaciones se encuentran el artículo «Westfalia en Carl Schmitt: otra leyenda» (Res publica. Revista de Historia de las Ideas Políticas, Vol. 18, Núm. 1 (2015), pp. 95-115 y el capítulo de libro «Frontera y colonia en el Derecho Internacional schmittiano: el papel vertebrador del Nuevo Mundo para la soberanía del Ius publicum europaeum» en ABRALDES, D. (coord.), Ideas que cruzan el Atlántico: Utopía y Modernidad Latinoamericana, Escolar y Mayo, Madrid, 2016, pp. 49-67.

1 ROHDE, D., «My Guards Absolutely Feared Drones. Reflections on Being Held Captive for Seven Months by the Taliban», en BERGEN, P. L. y ROTHENBERG, D. (ed.), Drone Wars. Transforming Conflict, Law and Policy, Cambridge University Press, Nueva York, 2015, pp. 9-11, p. 10.Traducción personal. 


\begin{abstract}
«[El dron] es un «objeto violento no identificado»: desde el momento en que intentemos pensarlo bajo las categorías establecidas, una agitación intensa afecta a nociones tan elementales como las de zona o lugar (categorías geográficas y ontológicas), de virtud o de valentía (categorías éticas) de guerra o de conflicto (categorías estratégicas y jurídico-políticas a la vez)».
\end{abstract}

GRÉGOIRE CHAMAYOU²

\title{
I. La configuración espacial de la guerra moderna: los fundamentos de la distinción tierra/mar
}

La conexión entre el territorio y la guerra fue magníficamente expuesta por Carl Schmitt en sus principales obras políticas, como El nomos de la tierra, El concepto de lo político, Teoría del partisano o Tierra y mar. El propósito de este artículo es mostrar cómo en Schmitt las condiciones espaciales determinan la configuración de diferentes tipos de política, de enemistad y de guerra y cómo con su crítica al uso de la aviación en los conflictos bélicos intuye lo que después será considerado el cambio más radical experimentado en la guerra: los aviones sin piloto.

Según Carl Schmitt, si el Ius publicum europeaum constituyó la etapa de mayor gloria para la humanidad fue porque dicho pensamiento jurídico se articuló en torno a un concepto de guerra limitada y contenida, que Schmitt llamó «guerra en forma» ${ }^{3}$. Junto a esta noción de conflicto bélico se dio en la Modernidad una específica manera de entender las relaciones políticas, la basada en la consideración del adversario como enemigo justo, que en el ámbito de la guerra permitía que los ejércitos que se enfrentaban entre sí se reconocieran mutuamente como combatientes y no como enemigos injustos. La clave de esta acotación de la guerra y de la enemistad es la dimensión espacial de la batalla, en concreto, su limitación en un territorio muy concreto, el europeo. La guerra que tenía lugar dentro de Europa era muy contenida y mitigada ya que el verdadero conflicto se desarrollaba fuera de las fronteras europeas. Se encuentra, pues, en Schmitt, una estructura espacial tripartita (continente, mar y colonias), siendo los espacios libres marítimos y coloniales aquellos donde los instintos bélicos se verían satisfechos, dado que en esos espacios no regía el derecho clásico europeo de la Modernidad. Y esa división permite hablar de dos tipos de guerra, aquella en la que sí están vigentes los principios del Ius publicum europaeum (guerra terrestre o, más bien, continental europea) y aquella en la que no (la guerra marítima y colonial). A Schmitt le gusta referirse al «teatro de la guerra», expresión que utilizaba Clausewitz para referirse a «una porción del espacio en la que prevalece la guerra y cuyos límites están protegidos, por lo que posee cierta independencia» ${ }^{4}$. Podemos afirmar que esa escenificación correspondía únicamente al territorio europeo.

2 CHAMAYOU, G. Théorie du drone, La fabrique Ed., París, 2013, p. 26. Traducción personal.

3 Las guerras ya no estarán basadas en «causas justas» ni asentadas en principios teológicos ya que los fundamentos de las relaciones interestatales serán exclusivamente políticos, basados en la «razón de estado».

4 ClAUSEWITZ, C. von, De la guerra, Ediciones Obelisco, Barcelona, 2005, libro V, cap. II, I, p. 308. 
El espacio europeo es creador de derecho, pero en el mar, por la idiosincrasia propia del elemento marítimo, no son posibles las tomas soberanas de tierra y, por ello, tampoco es realizable la idea de derecho ligada al estado soberano ${ }^{5}$. El mar se convierte entonces en el lugar privilegiado para el desarrollo de la actividad privada ${ }^{6}$ y de guerras cuyo objetivo es dañar la economía de los países enemigos, pero no conquistar su territorio. El status del contrabandista o del pirata es sui generis. Se sirve de la libertad del mar y de la libertad del comercio y está sometido a un derecho muy especial, el de la jurisdicción de presas, institución fundamental que ilustra que el mar es un espacio no incluido en el derecho europeo pero que no está completamente libre de jurisdicción y que permite concebir la enemistad a partir de un tercer concepto de enemigo distinto al del justus hostis, ligado al estado, y al de enemigo injusto: el enemigo no estatal ${ }^{7}$. Las reglas del Ius publicum europaeum tampoco se aplican en las colonias y, en este caso, según Schmitt, no se va a generar ningún tipo de enemistad concreto hacia los nativos de las colonias. Estos amerindios no van a ser considerados enemigos de ningún tipo ya que eran percibidos por los europeos como seres políticamente nulos y vacuos. No merecían ningún reconocimiento, mucho menos el de enemigo, que presuponía la aceptación del adversario como ente político ${ }^{8}$.

\section{La guerra aérea y el fin de la guerra clásica del Ius publicum europaeum}

En el siglo XX la geografía de la guerra tuvo que incorporar a la distinción tierra/mar propia del Ius publicum europaeum el elemento aéreo. La aviación, entendida por Schmitt como la agregación de un tercer elemento espacial, es concebida en un principio como un aumento de los medios de la guerra terrestre y marítima, representando una diferencia de grado respecto a ese tipo de guerras. Sin embargo, para Schmitt implica ya un cambio distintivo de las condiciones de la guerra, ya adelantado por la aparición del submarino. Ambas novedades, la sumergible y la aérea, rompen el plano del mar hacia arriba y hacia abajo ${ }^{9}$. Pero el avión supuso un cambio cualitativo aún mayor que la del submarino porque

5 O, en cualquier caso, sólo habría sido realizable por Inglaterra, estado eminentemente marítimo: "La tierra firme pertenece ahora a una docena de Estados soberanos; el mar, a nadie, a todos y, en realidad, a uno sólo: Inglaterra”, SCHMITT, C. Tierra y mar. Una reflexión sobre la historia universal, Trotta, Madrid, 2007, p. 67.

6 «La guerra marítima era y siguió siendo, en sí misma y de forma inmediata, una guerra de botín, que estaba dirigida directamente contra la propiedad privada enemiga e incluso neutral. Era y continuó siendo guerra comercial, y es preciso tener en cuenta que el comercio, según el criterio del siglo XIX, era libre por su naturaleza, es decir, no-estatal, y asunto privado». SCHMITT, C. El Nomos de la Tierra en el Derecho de Gentes del Ius publicum europaeum, Comares, Granada, 2002, p. 339.

7 «Así pues, el significado extraordinario, para el Derecho de Gentes, de la jurisdicción de presas reside en que crea la posibilidad de aplicar justicia y reciprocidad también frente al enemigo no-estatal». Ibid., p. 341.

8 Cfr., SCHMITT, C. Tierra y mar, op. cit., p. 59. Aspecto que el teórico Benno Teschke critica en su artículo «Fatal attraction: a critique of Carl Schmitt's international political and legal theory», International Theory, Cambridge University Press, 3:2, pp. 179-227, p. 195.

9 El desarrollo de la electricidad y la radio forman parte de la alteración de las coordenadas espacio-temporales clásicas que introduce el elemento aéreo: «Si pensamos además que no sólo las aeronaves surcan el espacio sobre tierras y océanos, sino que también las ondas radiofónicas de las emisora de todos los países cruzan ininterrumpidamente la atmósfera y dan la vuelta al planeta en un instante, nos será más fácil creer que ahora no se ha conquistado tan sólo una nueva tercera dimensión, sino que se ha irrumpido en un tercer elemento, el aire...». SCHMITT, C. Tierra y mar, op. cit., p. 80. 
una vez que se introduce la aviación en la guerra, el mar deja de ser zona libre con su tipo de guerra específico (guerra marítima) y entra en la órbita de la guerra aérea:

Como consecuencia de la combinación de la aviación con la guerra marítima, el espacio de alta mar, el mar libre, ya no es el espacio previsto como escenario en el sentido de las instituciones clásicas del derecho de guerra marítima. Frente a ello, la guerra aérea independiente librada contra el potencial bélico del enemigo, y que no se desarrolla en el marco de las operaciones bélicas puramente terrestres o puramente marítimas, representa en mucho mayor grado un nuevo tipo de guerra que no es posible definir, por analogía o paralelo, a base de las reglas de la antigua guerra terrestre o guerra marítima ${ }^{10}$.

Una de las diferencias que distinguía a la guerra terrestre de la marítima, según Schmitt, es que la primera tenía como objetivo ocupar un territorio y a través de esta ocupación se establecía una relación positiva de protección a cambio de la obediencia de la población, lo cual conducía a la acotación de la guerra. Por el contario, la guerra marítima tenía como fin la mera obtención de un botín y ya presentaba elementos de destrucción y discriminación que se agudizarían con la guerra aérea, como los bloqueos de zonas terrestres, lo cual creaba una relación negativa con la población bloqueada, pues en estas situaciones el atacante está demasiado lejos de la tierra como para entablar un contacto positivo. Para Schmitt, la guerra aérea no tiene fines territoriales ni económicos, sino simplemente destructivos y de mostración de fuerza: «no es una guerra de botín, sino que genera destrucción» ${ }^{11}$. La categoría «aire» ${ }^{12}$ rompe el equilibrio e introduce una total discriminación, se ataca cualquier objetivo, militar o civil ${ }^{13}$, sin establecer contacto con la población atacada. El «teatro de la guerra» se desvanece y quedará totalmente destruido con el uso de drones, como explicaré a continuación:

Considerado desde el punto de vista espacial, el cambio se revela por el hecho de que, con referencia al espacio aéreo, ya no puede hablarse como hasta ahora de un escenario de guerra. A partir del siglo XVII, desde los comienzos de la guerra interestatal europea, los hombres se habían acostumbrado a la imagen de un escenario de guerra, un theatrum de la guerra terrestre. También fue aún posible, aunque no con la misma precisión, colocar al lado de la imagen de un escenario de la guerra terrestre la imagen de un escenario de la guerra marítima. La guerra aérea independiente, en cambio, si bien tiene un espacio propio, ya no tiene, sin embargo ni escenario ni espectadores ${ }^{14}$.

10 SCHMITT, C. El Nomos de la Tierra en el Derecho de Gentes del Ius publicum europaeum, op. cit., p. 347.

11 Ibid., p. 349.

12 Es interesante cómo en Schmitt esta categoría «aire» también implica el elemento «fuego» por los motores que hacen posible el funcionamiento de los aviones y por las bombas que se lanzan desde ellos. Cfr. SCHMITT, C. Tierra y mar, op. cit., p. 80.

13 «El recurso a la aviación vuelve imposible la simetría o la relación estratégica sobre una misma superficie. Llama naturalmente a la destrucción sin distinción entre combatientes». RAMEL, F., «Carl Schmitt contre l'idée de l'État mondial » en Carl Schmitt. Concepts et usages (ed. Serge Sur), CNRS Éditions, París, 2014, pp. 57-71, p. 62. Traducción personal.

14 SCHMITT, C. El Nomos de la Tierra en el Derecho de Gentes del Ius publicum europaeum, op. cit., p. 352. 
Si se analiza el aire desde la perspectiva de una filosofía geográfica, éste no debe ser entendido como un plano añadido o superpuesto a la tierra y al mar ${ }^{15}$. Según Schmitt, es erróneo pensar que en el espacio aéreo situado sobre la tierra rigen las normas de la guerra terrestre y que en el espacio aéreo ubicado sobre el mar rigen las normas de la guerra marítima. El aire, siendo un elemento diferente a tierra y mar, genera un tipo de guerra categorialmente distinta a los otros dos tipos de guerra.

El mar no es la tierra, pero ambos comparten la posibilidad de imaginar su continuación al mirar su horizonte porque, de hecho, tienen uno. Pero no podemos pensar o plantear la continuación del cielo hacia arriba. Los primeros testigos del ataque aéreo sabían de la existencia de planetas y estrellas «más arriba», pero ese lugar indeterminado por encima de las cabezas casi no es medible por la percepción, quizás sólo por la imaginación. El «más allá» del mar sí es concebible porque se mueve en el mismo plano horizontal que la tierra, sólo hay que continuar la línea. La mayor altura que se puede pensar en la guerra moderna es la alcanzada por una flecha o un cañón en su parábola. El espacio situado más arriba pertenece a la divinidad. Pero el ataque aéreo no es ni horizontal ni curvo, crea una línea vertical directa, va de arriba abajo ${ }^{16}$. Hasta entonces, el aire era un espacio no manipulable por el hombre para la guerra, cuando la muerte caía de arriba a abajo era en forma de fenómeno natural o divino, pero no por la acción de los humanos. Esta pérdida de limitación vuelve la guerra completamente deshumanizada por esa falta de contención.

Proporciones y medidas se alteran más aún y las posibilidades de dominio del hombre sobre la naturaleza y sobre otros hombres se extienden a insospechados dominios. Es comprensible que el arma aérea se caracterizase precisamente por ser «arma espacial», ya que los efectos revolucionarios que de ella se derivaron en lo espacial fueron singularmente grandes, inmediatos y evidentes ${ }^{17}$.

La tierra y el mar, incluso siendo este último el espacio de la no-ley, juegan en el plano de la horizontalidad, lo que permite crear varias dimensiones lineales: adentro-afuera, ley y no-ley, continente y mar, potencias-terrestres y potencias-marítimas, como un tablero de ajedrez que divide en dos el espacio y determina a los contrincantes. Sin embargo, el aire introduce la verticalidad aumentando el sentimiento de indefensión porque el fuego viene de arriba, no se encuentra en frente, obliga a alzar la mirada y a buscar un refugio que cubra, que haga de techo, que salvaguarde las cabezas. Estados Unidos es el agente que inicia la guerra área, la que rompe con la dinámica estratégica del derecho moderno, la que introduce la discriminación del adversario. En este caso el enemigo no solo es criminalizado, sino que es colocado en el espacio en una situación asimétrica y de inferioridad. Si como consecuencia de la alteración de los planos espaciales y el horizonte deja de haber teatro en la guerra aérea, también desaparecen los espectadores, según Schmitt. La relación entre el atacante y

15 «[E]l espacio aéreo, en cambio, se convierte en una dimensión propia, un espacio propio que, como tal, no enlaza con las superficies separadas de tierra y mar, sino hace caso omiso de su separación, distinguiéndose así esencialmente en su estructura, tan sólo por esta razón, de los espacios de los otros dos tipos de guerra». Ibid., p. 353.

16 «El piloto de un bombardero de un avión que efectúa vuelos en picado utiliza sus armas contra la población del territorio enemigo de forma vertical, lo mismo que San Jorge utilizaba su lanza contra el dragón». Ibid.p. 355.

17 SCHMITT, C. Tierra y mar, op. cit., p. 80. 
la población se desvanece porque no están en el mismo campo de percepción, ni en un nivel espacial semejante, rasgo que se intensificará aún más en el caso del uso de drones: «En el bombardeo desde el aire, se hace absoluta la ausencia de relación entre el beligerante y el suelo y la población enemiga que se encuentra en él...» ${ }^{18}$.

Según Schmitt, existe una correlación entre el mayor perfeccionamiento de las armas de destrucción y el carácter discriminatorio y moralizante de la guerra. Se pierde la contención de la guerra clásica articulada en torno a las nociones de «guerra en forma» y «enemigo», pues el que tenga mejores armas creerá que las tiene porque defiende la «causa justa» y calificará al enemigo de «criminal». Contra el criminal cualquier medio es válido y, por ello, la guerra ya no puede ser acotada sino total, abandonando toda limitación : «el vencedor considerará la superioridad de sus armas como una prueba de su iusta causa y declarará criminal al enemigo, puesto que ya no es posible realizar el concepto de iustus hostis» ${ }^{19}$. En cierto sentido, se recuperan las formas medievales y la noción de causa justa, pero ahora atravesadas por los frutos de la revolución técnica e industrial.

Cada vez resulta más difícil mantener limpias las manos en ese trabajo y guerrear de tal manera que la guerra se diferencia suficientemente del oficio de la policía por un lado y del oficio del carnicero y aun del desollador por el otro [...] A esto se añade que los inventos empujan a la guerra a ir más allá de todos los límites y que las nuevas armas suprimen todas las diferencias entre el combatiente y el no-combatiente. Con esto se viene abajo el presupuesto del que vive la consciencia estamental del soldado, con esto va a la par el declive de las formas caballerescas. Todavía Bismarck rechazó la propuesta de hacer comparecer a Napoleón III ante un tribunal. Bismarck consideraba que no tenía competencia para hacer eso, pues era su adversario ${ }^{20}$.

\section{Drones y guerra futura: armas sin soldados}

Tanto Schmitt como Jünger ya profetizaron cómo la mejora de los medios técnicos iría ligada a nuevas formas de destrucción y a la inauguración de una guerra sin límites. A finales del siglo XX y comienzos del XXI el perfeccionamiento de la técnica da lugar a un nuevo tipo de arma, un avión no tripulado llamado dron, cuya utilización supondrá un cambio cualitativo para la epistemología de la guerra. El dron desdibuja definitivamente los rasgos de las contiendas típicas del Ius publicum europaeum y contribuye a forjar una nueva noción de conflicto bélico muy diferente a la de la Modernidad. El impacto de los drones en la guerra ha sido tratado hasta ahora generalmente desde la óptica militar o jurídica, pero merece una mayor atención filosófica ${ }^{21}$. ¿Hasta qué punto fue Schmitt capaz de imaginar que la evolución de la aviación daría lugar a un arma sin soldado?

18 SCHMITT, C. El Nomos de la Tierra en el Derecho de Gentes del Ius publicum europaeum, op. cit., p. 353.

19 Ibid., p. 354.

20 JÜNGER, E. La emboscadura, Tusquets, Barcelona, 2011, p. 146.

21 Por ello, me serviré de autores como Grégoire Chamayou, Hugh Gusterson o Klem Ryan, que han dado a sus enfoques una perspectiva de corte más filosófico-político. Por ejemplo, para Chamayou el arma no es un mero instrumento, sino que determina la estructura de la acción que va a desencadenar y, por ello, según él, la filosofía debe mostrar interés en este fenómeno de cara a construir una «teoría crítica de las armas» (CHAMAYOU, G., op. cit., p. 28.). 
El dron forma parte de la guerra aérea y, en ese sentido, asimila los rasgos de la aviación: la distancia que separa al arma de su adversario es mayor que la que se da en las guerras terrestres o marítimas, se trata al enemigo como si fuera un criminal y se enmarca en un contexto de guerra justa. Pero si uso va a transformar aún más el concepto de guerra es por la nueva variable que introduce respecto a la guerra aérea: la enorme distancia que se establece entre el piloto y su arma. Como ya hemos visto, las diferentes formas de concebir el espacio generan distintas necesidades armamentísticas y, por tanto, diferentes tipos de guerra. En la medida en que el avance de la tecnología permite una enorme distancia entre el dron y el soldado, el concepto de espacio bélico se modifica. Además, pone en entredicho el concepto de combatiente o soldado ya que éste no se halla junto a su arma en la batalla. Por último, una guerra con drones, al igual que una guerra aérea, considera que el enemigo al que se enfrenta es un criminal. Y la desvinculación física y humana que se establece entre el piloto y el objetivo es tan extrema que éste es, aún más que en la guerra aérea, un mero blanco al que abatir sin ninguna consideración hacia su status como enemigo político. Las nociones que se van a ver afectadas a nivel teórico por la guerra de drones son, pues, la del campo de batalla, la del combatiente y la del enemigo, transformaciones que desarrollo a continuación.

En primer lugar, el dron rompe las coordenadas espacio-temporales de la guerra. El espacio queda alterado desde el momento en el que la acción del dron es ordenada y dirigida a una enorme distancia. Se crea una separación entre el lugar de la decisión y el lugar de la ejecución o, dicho con otras palabras, entre el soberano y la guerra. Se puede pensar que esto ha ocurrido en todas las guerras, que las decisiones bélicas se han tomado en el estado y las acciones militares se han llevado a cabo en el campo de batalla. El propio Schmitt indica que un cambio fundamental de la guerra naval consistió en la incorporación de cañones a los barcos, pues supuso la aparición del ataque a distancia ${ }^{22}$. Posteriormente, la distancia que separará a un piloto de un caza de su objetivo será mucho mayor que la que separaba a un soldado medieval de su contrincante, hasta el punto que la guerra aérea supone para Schmitt el comienzo de un tipo de guerra discriminadora y destructora. Aun así, considero que en estas formas de entender la distancia está en juego una mera diferencia de grado. El piloto del avión puede ver desde su cabina el terreno que va a destruir, la explosión y el humo causados por las bombas que lanza. Sin embargo, el piloto del dron no se halla de ninguna manera cerca del lugar de la batalla y, sin embargo, puede ver su objetivo con mayor «definición» que el piloto de un avión gracias a la cámara incorporada en el dron. Esto significa que la diferencia de distancia no es de grado, es categorial, primero, porque el soldado está separado de su arma y segundo, porque trabaja en el ámbito de la representación virtual. No es mi objetivo discutir si la percepción del piloto es más vívida o no desde un simulador o desde la cabina de un avión, sino señalar que las condiciones de la percepción han variado y que la acción a partir de un «simulador» rompe con las coordenadas clásicas de la acción bélica ${ }^{23}$.

22 Hasta ese momento el enfrentamiento entre galeras «era un simple combate terrestre sobre cubiertas de navíos». SCHMITT, C. Tierra y mar, op. cit., p. 38.

23 No voy a centrar la discusión en las consecuencias psicológicas que conlleva el hecho de matar a distancia. Hay estudios que confirman que el impacto es mayor al matar a un objetivo lejano que matar sobre el terreno, otros concluyen lo contrario. Pero las siguientes declaraciones de un piloto de dron reflejan las alteraciones personales que se derivan de una guerra de drones: «Una de las sensaciones más extrañas que tengo es cuando salgo del GCS [Ground Control Station] y me doy cuenta de que «vale, no estoy allí». Voy a encontrarme con mi 
Todo esto ocasiona que la noción de «campo de batalla» desaparezca ${ }^{24}$. Si antes, por dicho término, se entendía el lugar acotado y delimitado donde tenía lugar el conflicto y donde regía el ius belli, ahora el campo de batalla es la tierra entera - algo que ya anticipó Schmitt al referirse a la aviación - y esto por dos razones: porque el enemigo, considerado como terrorista o criminal puede hallarse en cualquier lugar del planeta y, porque si se acepta que el piloto del dron forma parte de la guerra, el lugar desde el que interviene, por muy alejado que esté del foco del conflicto, también se incorpora al espacio de la guerra:

De manera convergente, todo un sector de juristas americanos afirma hoy que la noción de «zona de conflicto armado» ya no debe ser interpretada en un sentido estrechamente geográfico. A esta concepción geo-centrada, supuestamente caducada, oponen otra, objetivo-centrada, unida a los cuerpos de los enemigos-presa, según la cual la zona de conflicto armado «va donde ellos vayan, ya sin ninguna consideración por la geografía» ${ }^{25}$.

Discrepo con Chamayou en que el territorio o la geografía hayan perdido importancia. Considero que el paradigma de un único centro o núcleo territorial donde tiene lugar el conflicto ha dado lugar a un contexto con múltiples espacios. Se puede argumentar que la guerra siempre ha tenido varios frentes. Pero esos frentes conformaban unidades individuales de decisión y ejecución, dependientes todas ellas de un mando central. La dislocación espacial que conlleva el uso de drones se produce porque la decisión está separada de la ejecución y porque el espacio que ocupa la guerra no es sólo físico, sino que invade también el ámbito virtual. Klem Ryan habla de «disociación»y «desespacialización»:

El término colectivo que uso para las implicaciones de esta falta de compromiso es «disociación», que surge de, al menos, tres formas distintas, cada una de ellas exagerada en la medida en que la distancia entre beligerantes aumenta: disociación de los agentes respecto de sus actos violentos, disociación de los objetivos respecto de la fuente de la violencia dirigida contra ellos, y disociación del público respecto de la violencia cometida en su nombre ${ }^{26}$.

mujer para comer. Dejaré de hacer una misión y me pasaré por el partido de fútbol de mi hijo. Aquellos son dos mundos muy, muy diferentes. Y tú estás dentro y fuera de aquellos mundos diariamente. Tengo que combinar aquellos dos mundos. Todos los días. Varias veces al día. Así que estoy allí y después no estoy allí y después estoy allí otra vez [...] Quizás incluso no seguiremos llamándolos pilotos». Pilot Nellis Air Force Base, Las Vegas, «It is War at a Very Intimate Level», entrevista dirigida y editada por ROTHENBERG, D. en BERGEN, P. L. y ROTHENBERG, D. (ed.), op. cit., pp. 113-117, pp. 116-117. Traducción personal.

24 «Era tan obvio para la mayoría de teóricos y juristas de los siglos XVIII y XIX que la guerra tenía lugar en campos de batalla que eran claramente distinguibles de cualesquiera otros espacios que esto no justificaba una mención explícita. Sólo a finales del siglo XIX y a principios del XX, como se desarrollaron nuevas tecnologías armamentísticas, especialmente con el desarrollo de la guerra aérea, la necesidad de definir el campo de batalla se convirtió en evidente». RYAN, K., «What's wrong with Drones? The Battlefield in International Humanitarian Law» en EVANGELISTA, M. y SHUE, H. (ed.) The American Way of Bombing. Changing Ethical and Legal Norms, from B-17s to Drones, Cornell University Press, Nueva York, 2014, pp. 207-223, p. 212. Traducción personal.

25 CHAMAYOU, G., op. cit., pp. 85-86, expresión de Kenneth Anderson, «Self-Defense and Non-International Armed Conflict in Drone Warfare», Opinio Juris, 22/10/2010, http://opiniojuris.org/2010/10/22/self-defenseand-non-international-armed-conflict-in-drone-warfare.

26 RYAN, K., op. cit., p. 213. Traducción personal. 
El antropólogo Hugh Gusterson prefiere utilizar el concepto «respacialización», término que considero más correcto que «desespacialización», pues, el espacio no desaparece o pierde importancia, sino que se desdobla o multiplica. Por un lado, está el espacio en el que el dron mata, por otro, el espacio de trabajo aparentemente pacificado desde el que el piloto del dron dirige el arma o, dicho con otras palabras, el campo de batalla y la oficina. Como ya he señalado, si se acepta que el piloto del dron es un combatiente, habrá que considerar que el simulador y el edificio desde el que maneja el arma también forman parte del campo de batalla, aunque esté situado a miles de kilómetros del mismo:

[O]tra manera de pensar esta situación es insistir en que si un combatiente actúa desde un lugar, entonces por definición, ese lugar es parte del campo de batalla. Si es así, el manipulador del dron no se ha retirado tanto del campo de batalla ya que ha globalizado el campo de batalla, trayendo el campo de batalla, o fragmentos experienciales de él, dentro de las fronteras nacionales de la patria ${ }^{27}$.

Esta falta de acotamiento del espacio dedicado a la guerra produce una confusión respecto a qué se considera espacio privado o familiar y qué espacio de trabajo. Como el piloto del dron se encuentra muy alejado del lugar donde el dron actúa, para él, "ir al trabajo" no es marcharse a la guerra en el sentido tradicional de acudir al campo de batalla, sino presentarse en la oficina en un horario concreto y disfrutar del ámbito familiar una vez acaba la jornada laboral. Estas dos realidades son muy cercanas a efectos físico-espaciales, pero muy distintas desde la perspectiva de la vivencia de la guerra. Como ejemplo de la confusión que produce la alteración del espacio que se produce, Hugh Gusterson narra cómo en sus clases universitarias pregunta a sus alumnos si atacar el centro de drones supondría un acto de guerra o de terrorismo. Ellos responden sin dudar que formaría parte de la guerra. Cuando Gusterson les plantea qué ocurriría en el caso de que el piloto del dron fuera atacado si volviese conduciendo a su casa, la respuesta no parece tan clara ${ }^{28}$. Esto es una de las consecuencias de la dislocación del espacio que lleva consigo un avión cuyo piloto no está en el avión. La noción de campo de batalla se vuelve entonces dislocada, desdoblada o multiplicada.

$\mathrm{Al}$ igual que he mencionado que el uso de drones no acaba con la importancia del espacio, tampoco considero que implique la desaparición del estado y de su poder de decisión. Cada semana se reúnen en Washington más de cien personas dedicadas a la seguridad nacional y proceden a la elaboración de una «kill list» con los objetivos a matar. Lo denominan «el martes del terror» ${ }^{29}$. Esto muestra, en parte, que el centro desde el que se toma la decisión de atacar sigue siendo el estado soberano. No hay que olvidar que el uso de drones es utilizado especialmente en la lucha contra grupos terroristas, en un tipo de conflicto denominado por el artículo 3 de la Convención de Ginebra de 1949 como NIAC (Non International Armed

27 GUSTERSON, H., «Towards an Anthropology of Drones: Remaking Space, Time, and Valor in Combat en EVANGELISTA, M. y SHUE, H. (ed.) The American Way of Bombing. Changing Ethical and Legal Norms, from B-17s to Drones», Cornell University Press, Nueva York, 2014, pp. 191-206, p. 197. Traducción personal.

28 Cfr., Ibid., p. 199.

29 BECKER, J. y SHANE, S., «Secret «Kill List» Proves a Test of Obama's Principles and Will», New York Times, 29/03/2012 apud CHAMAYOU, G., op. cit., p. 69. 
Conflict), Conflicto Armado No Internacional. El NIAC se caracteriza por enfrentar a estados contra grupos no estatales. Según Rothenberg, a nivel jurídico se mantiene la diferencia combatiente/no combatiente, pero como el enemigo no es un estado y no cumple con la legalidad internacional los estados tienen más libertad para establecer cuáles son sus objetivos ${ }^{30}$. Es decir, la guerra de drones, de momento, no enfrenta a dos estados entre sí, sino a un estado contra un grupo terrorista ${ }^{31}$. Esto hace que la manera de concebir el tiempo también sufra alteraciones en este nuevo tipo de conflicto. No se sabe cuándo empiezan y cuándo acaban estas guerras contra el terrorismo porque las acciones del dron, al no tener lugar bajo las coordenadas clásicas del conflicto, no son consideradas como momentos de una guerra declarada, sino que adquieren la forma de ataques difícilmente enmarcables en la cronología de una guerra tradicional.

Otra especificidad de la guerra de drones es que el enemigo se ve privado de la posibilidad de responder inmediatamente al ataque, precisamente, por la distancia que le separa de su atacante. Esto provoca una asimetría o falta de proporcionalidad entre ataque y respuesta ya que esta última no es posible de llevar a cabo por aquél que es atacado. De ahí que lo que cambie, junto con la noción de campo de batalla, sea el concepto de combatiente. El soldado no va a la guerra, no entra en contacto con su enemigo, no toca su arma. Esto pone en cuestión que el piloto de drones sea un verdadero soldado y que el conflicto que se desarrolla sea una verdadera guerra ya que el enfrentamiento no es recíproco, sino unilateral. Un conflicto que no enfrenta a estados entre sí, en el que ya no se ocupa un territorio físicamente, en la que no hay soldados en el territorio enemigo, en el que no hay combatientes luchando, es un tipo de guerra no visto hasta ahora e, incluso, habría que preguntarse hasta qué punto eso se puede considerar una guerra. Lo que quiero subrayar con esto no es sólo la novedad que supone para la guerra un soldado separado de su arma, sino sobre todo la posibilidad de que en el futuro los soldados no sean humanos.

Chamayou se pregunta por la esencia del piloto de drones a propósito de la definición que Hegel da del soldado ${ }^{32}$. Según Hegel, todo combatiente queda definido por su arma y esto genera una relación de reciprocidad en virtud de la cual un soldado reconoce a su enemigo porque también él delimita su entidad por el hecho de portar un arma, es decir, el arma genera las posibilidades del reconocimiento del alter ego enemigo. En el caso del

30 «Los contextos en los que los drones están actualmente desplegados se comprenden mejor como conflictos no internacionales más que como internacionales. En conflictos armados no internacionales el principio de distinción [entre combatiente y civil] permanece, en efecto, pero su aplicación es más compleja legalmente, las fuerzas no estatales no pueden ser partes de tratados internacionales y no están obligadas por la provisión específica de las regulaciones, haciendo menos claros los mecanismos y procesos de determinación de objetivos». ROTHENBERG, D. «Drones and the Emergence of Data-Driven Warfare» en BERGEN, P. L. y ROTHENBERG, D. (ed.), op. cit., pp. 441-464, p. 447. Traducción personal.

31 Esto implica reconsiderar la propia noción de guerra: o se acepta que una guerra ya no se reduce al enfrentamiento entre varios estados y que puede consistir en un conflicto entre entidades estatales y no estatales, incluso únicamente entre entidades no estatales, o a este nuevo tipo de conflictos se le tendrá que denominar con otro nombre. De momento, prefiero referirme a guerra de drones ya que los drones pueden ser usados en todo tipo de conflictos, porque determinarán el futuro de la guerra contemporánea y porque, de momento, las coordenadas de la guerra clásica son las que nos permiten formular, aunque sea a través de su negación, lo que sea el nuevo tipo de conflicto que deparará el futuro.

32 CHAMAYOU, G., op. cit., pp. 269-270. Se refiere a la siguiente cita de Hegel: «Pues las armas no son otra cosa que la esencia de los luchadores mismos, que surge, de manera recíproca, sólo para ellos dos.» HEGEL, G.W.F. Fenomenología del espíritu, Abada, Madrid, 2010, [209], p. 463. Edición de Antonio Gómez Ramos. 
dron se fractura la continuidad arma-soldado, desaparece la quidditas del combatiente, no sólo porque el nexo con su arma está roto, sino porque al no reconocer al criminal como enemigo es imposible crear una relación de reciprocidad con él.

Que el enemigo en las guerras contemporáneas es criminalizado es algo que ya señaló con insistencia Carl Schmitt al referirse a la guerra aérea. El «enemigo» atacado por el dron, independientemente de que sea un civil, un guerrillero o un terrorista, no es un combatiente porque se ve privado de la posibilidad de combatir. La acción del dron se caracteriza por su unilateralidad: el piloto ataca pero no puede ser atacado. Esta imposibilidad de dar respuesta al ataque marca la imposibilidad de que se dé un verdadero combate y de que lo que se enfrenten sean verdaderos enemigos ${ }^{33}$.

Por más que el partisano, según la fórmula de Schmitt, permanezca esencialmente telúrico, el contra-partisano contemporáneo debe hacerse estratosférico [...] El dron aparece como la respuesta tardía a este problema: vuelve contra la guerrilla, pero bajo una forma radicalmente absolutizada, su antiguo principio: privar de enemigo al enemigo. Un partisano enfrentado a un ejército de drones no dispone ya de ningún objetivo a atacar $^{34}$.

Esto tiene como consecuencia que individuos civiles puedan ser considerados objetivos por su supuesta capacidad de llevar a cabo acciones terroristas en el futuro. Como lo que se persigue es un criminal y no un enemigo, su aniquilación justifica los medios. Chamayou señala que la guerra de drones se convierte en la persecución de una presa, es decir, en un ejercicio de caza muy alejado del concepto de guerra tradicional. Si la persona perseguida es concebida como una presa pierde su carácter de enemigo ${ }^{35}$. De hecho, los drones son conocidos como «predators» o «reapers», es decir, depredadores o segadores.

Como consecuencia de no reconocer al objetivo como un combatiente o un enemigo, sino como un criminal, la teoría de la guerra justa encuentra en el uso de drones un buen ámbito en el que justificarse ${ }^{36}$. La opinión pública puede llegar a entender que cuando el dron alcanza su objetivo no está llevando a cabo una campaña bélica, sino el asesinato de un criminal. Los estados que utilizan drones aseguran que sus objetivos son terroristas o guerrilleros, es decir, que están fuera de la ley, que son criminales y que por ello es legítimo atacarles de esta manera ${ }^{37}$.

33 «El escudo del dron «MQ 9 Reaper» representa la parca, con un rictus inquietante y gotas de sangre sobre su cuchilla, con el lema: «Que mueran los otros»». CHAMAYOU, G., op. cit., p. 133. Traducción personal.

34 Ibid., p. 93. Traducción personal.

35 «i la guerra se define en última instancia por el combate, la caza lo es esencialmente por la persecución».Ibid., p. 79. Traducción personal.

36 «En otras palabras, incluso si los drones son inconsistentes con los conceptos subyacentes al Derecho Humanitario Internacional y causan un profundo resentimiento y hostilidad de las poblaciones contras las que son desplegados, en tanto que sus objetivos son declarados «injustos», los recelos acerca de desplegar drones son fácilmente mitigados». RYAN, K., op. cit., p. 223. Traducción personal.

37 Por ello, Gusterson coincide con Chamayou en que la lucha con drones se asemeja más la caza que a una lucha. «En efecto, la manera en que operan los drones Predator y Reaper se parece más a la caza que a la guerra, dado que no existe la oportunidad de que el operador del dron pueda ser asesinado por su objetivo/adversario». GUSTERSON, H., op. cit., p. 201. Traducción personal. 
Hay que tener en cuenta que los drones no solo matan, también se dedican a labores de observación y vigilancia. Como dice Chamayou, no solo tienen ojos, también oídos ${ }^{38}$. Este control de la vida del objetivo, muy ligado a la gubernamentalidad foucaultiana, se realiza en base al análisis de las regularidades e irregularidades de la cotidianeidad del sujeto, de modo que cuando algo se sale de la norma de la cotidianeidad empiezan las sospechas y aumentan las posibilidades de proceder a la eliminación del individuo. Esto incide en la idea del objetivo como presa, no como enemigo. La observación, persecución y captura no son labores típicamente bélicas, sino un trabajo policial en su búsqueda de terroristas. Los ejércitos tradicionales se observan, es cierto, pero no se persiguen o capturan, sino que luchan entre sí:

El análisis de las formas de vida se define más precisamente como «la fusión del análisis de los lugares y del análisis geoespacial». Para tener una idea de que se trata, hay que imaginarse la sobreimpresión, sobre un mismo mapa numérico, de Facebook, de Google Maps y de un calendario de Outlook. Fusión de coordenadas sociales, espaciales y temporales; cartografía conjunta del socius, del locus y del tempus - es decir, de las tres dimensiones que constituyen, en sus regularidades pero también en sus discordancias, lo que es prácticamente una vida humana ${ }^{39}$.

La unilateralidad de la acción del dron es patente incluso a nivel perceptivo: ellos ven a sus víctimas, pero las víctimas no les ven a ellos. Esto implica, una vez más, el no reconocimiento del enemigo. Éste se ve privado de la capacidad de defenderse y también de la posibilidad de postular un ser humano que le ataca ${ }^{40}$. La víctima de un ataque aéreo tradicional, aunque no vea al piloto, presupone su existencia, y eso supone un acicate psicológico, puede gritarle o insultarle aunque no sea oído, pero ante un dron el mero hecho de alzar la voz pierde su sentido:

El hecho que el asesino y su víctima no estén inscritos en los «campos perceptivos recíprocos» facilita la administración de la violencia [...] lo que Milgram llama la ruptura de «la unidad fenomenológica del acto». Pulso este botón y una silueta desaparece en una explosión allá ${ }^{41}$.

El nombre técnico del dron dedicado a labores bélicas es «UCAV» (Unmanned Combat Air Vehicle), Vehículo Aéreo de Combate No Tripulado. «Unmanned» se traduce en jerga militar como «no tripulado» pero, atendiendo a la semántica del vocablo, se podría

38 CHAMAYOU, G., op. cit., p. 63.

39 Ibid., p. 72. Traducción personal. La definición de las formas de vida es de Tony Mason, Suzanne Foss y Vinh Lam, «Using ArcGIS for Intelligence Analysis», Esri Intenrational User Conference, 2012, http://proceedings. esri.com/library/userconf/feduc11/papers/tech/feduc-using-arcgis-for-intelligence-analysis.pdf.

40 Esta omnipotencia del dron que se advierte en su capacidad de ver, oír, atacar y matar sin ser vulnerado muestra un aspecto teológico que, según Noys, pese a su carácter parargonal -en línea con la teoría de Derrida- es constituyente del dron. NOYS, B. «Drone Metaphysics», Culture Machine, vol.16, 2015, pp. 2-3.

41 CHAMAYOU, G., op. cit., pp. 167-168. Chamayou se refiere a MILGRAM, S. Obedience to Authority: An Experimental View, Harper \& Row, Nueva York, 1974, p. 39. Traducción personal. 
interpretar que lo que designa especialmente es un objeto cuya esencia consiste en no ser humana, en no ser hombre o, como señala Chamayou, en no tener carne. El objetivo, sin embargo, sí tiene carne, de lo que carece es del derecho a ser enemigo y, por tanto, a ser tratado como prisionero de guerra, con todo lo que eso implica. Existe una ausencia de derechos por parte del objetivo y una falta de responsabilidad por parte del lado atacante, pues no hay sujeto al que imputar la responsabilidad ${ }^{42}$. El desarrollo de la técnica ha producido que las causas estén muy alejados de los efectos que éstas producen. Como señala Schmitt, esto es consecuencia de una división del trabajo que convierte la cadena de las causas en una sucesión infinita a través de la cual se va diluyendo poco a poco la responsabilidad:

El brazo humano que sostiene la bomba atómica, el cerebro humano que enerva los músculos de este brazo humano, no son, en el momento decisivo, un miembro del ser humano individual, sino una prótesis, una parte de la estructura técnica y social que produce la bomba atómica y la aplica. El poder del poderoso individual no es aquí más que el exudado de una situación que resulta de un sistema de una incalculablemente excesiva división del trabajo ${ }^{43}$.

Ya señalaba Schmitt que la técnica es abrazada en nuestra época porque parece lo más neutral. Como cualquiera puede utilizarla se identifica con la despolitización y como se considera, erróneamente, que la despolitización es sinónimo de paz, se concluye que la técnica es pacífica ${ }^{44}$. Sin embargo, Schmitt señala que la técnica no es neutral, precisamente porque cualquiera puede hacer uso de ella: «...hoy día la guerra más aterradora solo se realiza en nombre de la paz, la opresión más terrible solo en nombre de la humanidad» ${ }^{45}$.

A pesar del rápido avance de la tecnología, en el uso de drones todavía se mantiene cierto rasgo clásico de la guerra: el del enfrentamiento entre humanos. Ahora bien, en el futuro incluso ese aspecto será puesto en cuestión. Si se acepta que es plausible imaginar un futuro en el que la propia tecnología se haga con las variables de la decisión, la problemática aumenta. Aceptar el fin de la decisión es aceptar el fin de la soberanía y esto acarrea consecuencias graves para el derecho internacional. La dificultad de legislar en una guerra en la que no hay soldados sobre el terreno, en la que no está presente la materialidad del estado, los ejércitos, se perfila como uno de los grandes retos internacionales del futuro. Los últimos textos de Schmitt, especialmente El nomos de la tierra y Teoría del partisano,

42 Esto es más importante de lo que parece pues no existen las compensaciones ante errores que causan la muerte de civiles: «Uno de los mayores problemas con los drones en Waziristán del Norte cuando son asesinadas personas inocentes. Cuando esto ocurre, sus familias no obtienen ninguna compensación de nadie. Al menos, con otros tipos de ataques que matan civiles las familias reciben alguna compensación del gobierno». KHAN. A., «No One Feels Safe», entrevista dirigida y editada por ZUBAIR SHAH, P. en BERGEN, P. L. y ROTHENBERG, D. (ed.), op. cit., pp. 345-347, p. 346. Traducción personal.

43 SCHMITT, C. «Coloquio sobre el poder y sobre el acceso al poderoso», Revista de Estudios Políticos, $\mathrm{n}^{\circ} 78$, 1954, pp. 3-20, p. 17.

44 Dando por hecho erróneamente que despolitización es paz, cuando precisamente lo político permite la acotación de la guerra, única posibilidad real de la paz.

45 SCHMITT, C., El concepto de lo político, Alianza Editorial, Madrid, 2009. Versión de Rafael Agapito, p. 121. 
anticipan un futuro en el que la técnica hará que la guerra sea más cruel. Esta teoría profética de Schmitt esbozó, pero no llegó a definir con claridad ${ }^{46}$, un horizonte bélico en el que la enorme distancia entre el piloto y su arma provocaría, no ya la desaparición de duelo clásico, sino la propia inexistencia del combate.

\section{Referencias}

Chamayou, G. (2013), Théorie du drone, París: La fabrique.

Clausewitz, C. von (2005), De la guerra, Barcelona: Ediciones Obelisco.

Gusterson, H., (2014), Towards an Anthropology of Drones: Remaking Space, Time, and Valor in Combat, en Evangelista, M. y Shue, H. (eds.) The American Way of Bombing. Changing Ethical and Legal Norms, from B-17s to Drones, Nueva York: Cornell University Press, pp. 191-206.

Hegel, G.W.F. (2010), Fenomenología del espíritu, Madrid: Abada.

Jünger, E. (2011), La emboscadura, Barcelona: Tusquets.

Milgram, S. (1974), Obedience to Authority: An Experimental View, Nueva York: Harper \& Row.

Noys, B. (2015), Drone Metaphysics, Culture Machine, vol. 16.

Ramel, F. (2014), Carl Schmitt contre l'idée de l'État mondial, en Carl Schmitt. Concepts et usages (ed. Serge Sur), París: CNRS Éditions, pp. 57-71.

Rohde, D. (2015), My Guards Absolutely Feared Drones. Reflections on Being Held Captive for Seven Months by the Taliban, en Bergen, P. L. y Rothenberg, D. (ed.), Drone Wars. Transforming Conflict, Law and Policy, Nueva York: Cambridge University Press.

Ryan, K. (2014), What's wrong with Drones? The Battlefield in International Humanitarian Law, en Evangelista, M. y Shue, H. (ed.) The American Way of Bombing. Changing Ethical and Legal Norms, from B-17s to Drones, Nueva York: Cornell University Press, pp. 207-223.

Schmitt, C. (1954), Coloquio sobre el poder y sobre el acceso al poderoso, Revista de Estudios Políticos, $\mathrm{n}^{\circ} 78$, pp. 3-20.

Schmitt, C. (2002), El Nomos de la Tierra en el Derecho de Gentes del Ius publicum europaeum, Granada: Comares.

Schmitt, C. (2007), Tierra y mar. Una reflexión sobre la historia universal, Madrid: Trotta. Schmitt, C. (2009), El concepto de lo político, Madrid: Alianza. Versión de Rafael Agapito. Volpi, F. (2007), El poder de los elementos, Epílogo a Schmitt, C. Tierra y mar. Una reflexión sobre la historia universal, Madrid: Trotta.

46 Quizás porque el apego a la tierra que sentía Schmitt le impedía reconocer su disolución: «...la conclusión de Schmitt se tiñe de nostalgia: el hombre es hijo de la tierra y, mientras siga siendo hombre, no dejará de tomar de la tierra su energía - como el gigante Anteo, que pierde su fuerza cuando se levanta del suelo y pierde el contacto con su madre Gaia». VOLPI, F. «El poder de los elementos», Epílogo a SCHMITT, C. Tierra y mar, op. cit., p. 104. 